\title{
Universalização do saneamento básico: uma análise da abordagem de territórios rurais em Planos Municipais de Saneamento Básico do Brasil
}

\section{Universalization of basic sanitation: an analysis of the approach of rural areas in Municipal Basic Sanitation Plans}

Data de entrada: $26 / 02 / 2020$

- Data de aprovação: $12 / 08 / 2020$

Rafaela Franco $^{1 *}$ | Bárbara Furtado Barra ${ }^{1}$ Uende Aparecida Figueiredo Gomes ${ }^{1}$

DOI: https://doi.org/10.36659/dae.2022.024

ORCID ID

Franco R (D) https://orcid.org/0000-0003-3615-5357

Barra BF (iD https://orcid.org/0000-0002-4778-2084

Gomes UAF (D) https://orcid.org/0000-0002-2750-8635

\section{Resumo}

O Plano Municipal de Saneamento Básico (PMSB), principal instrumento da política municipal de saneamento, é normatizado pela Lei Federal 11.445/2007, que define os princípios do saneamento básico no Brasil, entre estes, o da universalização do acesso. No tocante ao planejamento, a Lei supracitada e seu Decreto Regulamentador 7.217/2010 definem que o recorte territorial do PMSB deve abranger áreas urbanas e rurais. 0 presente artigo objetiva analisar a abordagem do rural em PMSBs. Para tanto, foi realizada uma amostragem estatística com 2738 municípios brasileiros que haviam concluído seus respectivos planos, resultando em amostra de 390 municípios: 90 da macrorregião Sul, 92 do Sudeste, 76 do Nordeste, 68 do Centro Oeste e 64 do Norte. Verificou-se que apenas $44 \%$ dos planos estão disponíveis na Internet, em conformidade com a Lei 11.445/07 acerca da transparência das ações. Destes, 27\% não incluem o meio rural no processo de planejamento, o que incita um cenário de injustiça ambiental.

Palavras-chave: Planejamento. Transparência. Controle social. Consulta pública. Justiça ambiental. Rural. Desigualdade.

\section{Abstract}

The Municipal Basic Sanitation Plan (PMSB), the main instrument of municipal sanitation policy, is standardized by Federal Law 11.445/2007, which defines the principles of basic sanitation in Brazil, including universalization of access. Regarding the planning, the aforementioned Law and its Regulatory Decree 7.217/2010 define that the territorial outline of the PMSB should cover urban and rural areas. This article aims to analyze the rural approach in PMSBs. Therefore, a statistical sampling was performed with 2738 Brazilian municipalities that had completed their respective plans, resulting in a sample of 390 municipalities: 90 from the South macroregion, 92 from the Southeast, 76 from the Northeast, 68 from the Midwest and 64 from the North. It was found that only $46 \%$ of the plans are available on the Internet, in accordance with Law 11.445/07 on the transparency of actions. Of these, $27 \%$ do not include the rural area in the planning process, which incites a scenario of environmental injustice.

Keywords: Planning. Transparency. Social control. Public consultation. Environmental justice. Rural. Inequality.

\footnotetext{
1 Universidade Federal de Minas Gerais - Belo Horizonte - Minas Gerais - Brasil.

*Autora correspondente: rafaelafranco12agmail.com.
} 


\section{INTRODUÇÃO}

Em 2010, o acesso ao abastecimento de água e ao esgotamento sanitário foi considerado um direito humano pela Organização da Nações Unidas (ONU). Esse direito, todavia, tem sido recorrentemente violado, uma vez que existem 785 milhões de pessoas sem acesso à fonte de água melhorada ou com limitação de acesso. No que tange o esgotamento sanitário, a violação do direito ao acesso é ainda mais alarmante, totalizando 673 milhões de pessoas de todo o mundo que ainda praticam defecação a céu aberto (WHO/UNICEF JMP, 2019). Em particular na América Latina e no Caribe, há 15,5 milhões de pessoas sem acesso a banheiros, sendo que pessoas com renda mais baixa, residentes em áreas rurais e indígenas, são as mais afetadas por essa condição (WHO/UNICEF JMP, 2019).

Embora tenham sido alcançados avanços no sentido da universalização dos serviços de saneamento básico, ainda persistem grandes desigualdades de acesso ao saneamento adequado. Mundialmente, entre os determinantes para a exclusão do acesso, destaca-se a localização da moradia, sendo observadas diferenças de atendimento para as zonas urbanas e rurais. Neste sentido, segundo a Declaração da Rede Brasileira de Justiça Ambiental' ${ }^{1}$-RBJA, a injustiça ambiental, decorrente do modelo desenvolvimentista dominante no Brasil, expressa-se na exposição aos riscos ambientais provenientes das substâncias perigosas, na existência de moradias em encostas perigosas e em beiras de cursos d'água sujeitos a enchentes, nas moradias nas proximidades de depósitos de lixo tóxico, ou nas pessoas vivendo sobre gasodutos ou sob linhas de transmissão de eletricidade e sem acesso ao saneamento básico (HERCULANO, 2002). A ausência de acesso ao saneamento, em particular, é colocada na declaração como uma injustiça ambiental, em razão das desigualdades sofridas por certos grupos populacionais. Em áreas de privação socioeconômica, ocupadas por grupos minoritários, sem acesso às esferas decisórias do Estado e do mercado, a população sofre as consequências da falta de infraestrutura de saneamento, ausência de controle ambiental, desertificação, dentre outros, más condições ambientais de vida e trabalho. Acselrad (2002) reforça essa ideia ao discorrer sobre a transferência do custo ambiental aos mais vulneráveis, delegando a posse do território e das riquezas naturais às pessoas de classe econômica mais alta.

No tocante às desigualdades de acesso ao saneamento no Brasil, o Plano Nacional de Saneamento (PLANSAB) identifica que esse déficit está especialmente concentrado em grupos compostos por famílias de baixa renda, residentes nas favelas e áreas rurais, nas macrorregiões Norte e Nordeste (BRASIL, 2013; BRASIL, 2019a). A distribuição desigual do déficit de acesso ao saneamento é materializada pelos determinantes de acesso, sendo identificados, neste contexto, cor da pele, etnia, escolaridade, ou se a chefia da família é feminina ou masculina (FARIA, 2018; SALES, 2018; LUZZA, 2019).

Luzza (2019), por meio de análise de dados do Cadúnico, para o ano de 2017, verificou que a possibilidade de ausência de canalização interna para abastecimento de água na região Norte é de $30,1 \%$; já para a região Sul é de $4,3 \%$. A ausência de banheiro na região Nordeste é de $13,4 \%$, enquanto na região Sudeste é $1,7 \%$. Para a ausência de coleta de resíduos sólidos domésticos (RSD), na região Norte a porcentagem é

\footnotetext{
${ }^{1}$ No Colóquio Internacional sobre Justiça Ambiental, realizado em Niterói, na Universidade Federal Fluminense, de 24 a 27 de setembro de 2001, foi criada a Rede Brasileira de Justiça Ambiental, a partir do conceito de Justiça Ambiental criado nos EUA. A declaração é transcrita no artigo Riscos e desigualdade social: a temática da Justiça Ambiental e sua construção no Brasil, publicado no 1 Encontro da ANPPAS, 2002.
} 
de $37,3 \%$ e na região Centro-Oeste é de $15 \%$, comprovando as desigualdades macrorregionais para o acesso aos serviços de saneamento. A respeito da determinante localização dos domicílios em áreas rurais ou urbanas, o estudo de Luzza (2019) indica que, na área rural, o índice é de $76,5 \%$ de domicílios com canalização interna por poço, nascente ou rede geral, ao passo que, para a área urbana, essa porcentagem alcança 93,8\% dos domicílios, com uso predominante por rede. Acrescenta-se que enquanto $11,5 \%$ dos domicílios do meio urbano possuem déficit de atendimento para serviços de esgotamento sanitário, esse valor aumenta para $60,3 \%$ nas áreas rurais, nas quais os esgotos são destinados para fossas rudimentares, ou valas, rios, mar ou outro destino (BRASIL, 2019a).

Além de um direito humano fundamental, a universalização do acesso ao saneamento básico é um dos princípios da Política Federal e Diretrizes Nacionais do Saneamento Básico, estabelecidas, no Brasil, pela Lei Federal 11.445/2007. A supracitada lei ainda define o Plano Municipal de Saneamento Básico (PMSB) como instrumento da política municipal de saneamento básico (BRASIL, 2007). Nesse contexto, verifica-se que o PMSB é essencial na identificação das disparidades, das potencialidades e dos locais de maior vulnerabilidade sanitária de cada município, bem como, ao definir programas, projetos e ações para melhorias sanitárias no futuro, indica a equidade ou o acirramento de desigualdades.

A abordagem do território rural nos PMSBs é uma obrigatoriedade segundo o marco regulatório da área de saneamento, de modo que a ausência da consideração do meio rural nos documentos evidencia uma exclusão de grupos das políticas públicas, bem como de projetos futuros que preveem melhorias sanitárias. Esse quadro reforça e perpetua o cenário de injustiça ambiental ao qual a população rural está exposta.
Diante da importância de conhecer a realidade rural, com todas suas especificidades, assim como de promover uma igualdade da situação ambiental na qual as populações se inserem, o presente artigo tem como finalidade analisar a abordagem territorial dos PMSBs no Brasil à luz do marco teórico da justiça ambiental. Nesse contexto, buscou-se uma análise dos planos como orientadores da política municipal do saneamento no território municipal, de forma a promover a equidade, a inclusão e a justiça ambiental. Neste sentido, não abordar o rural nos PMSBs reafirma a ausência de justiça ambiental, a qual se perpetuará por 20 anos, período de vigência dos documentos.

\section{FUNDAMENTAÇÃO TEÓRICA \\ 2.1 Justiça Ambiental}

A origem do termo Justiça Ambiental se ampara nos movimentos sociais que ocorreram nos Estados Unidos a partir de 1960, em busca de direitos dos afrodescendentes. Nessa época, essas comunidades e a população de baixa renda encontravam-se submetids a uma maior exposição aos riscos ambientais decorrentes da disposição de resíduos químicos e radioativos nas proximidades dos locais onde essa parcela da população residia (ACSELRAD, HERCULANO e PÁDUA, 2004; RAMMÊ, 2012).

Bullard expõe o conceito de justiça ambiental como a luta contra a desigualdade ambiental, a qual se apresenta sob duas maneiras: "proteção ambiental desigual" e/ou "acesso desigual aos recursos ambientais" (BULLARD, 2004). Assim, trata-se do acesso justo e equitativo aos recursos ambientais, além do acesso às informações relevantes sobre os riscos ambientais, em processos democráticos e participativos, que assegurem que nenhum grupo sofra as consequências desproporcionais ambientais negativas, bem como seja excluído das políticas públicas (ACSELRAD, 
MELLO e BEZERRA, 2009), não estando submetidos a cenários de injustiça ambiental.

Scott (2014) acrescenta a integração e a inclusão das comunidades afetadas de forma desproporcional pela degradação ambiental nas políticas ambientais e nas tomadas de decisão no movimento pela Justiça Ambiental. Para esse autor, essa luta amplia-se, também, para o planejamento urbano, os serviços de saneamento básico e aos trâmites de decisões apoiadas nas políticas públicas. No mesmo âmbito, Zhouri (2008, p. 104) apresenta o conceito de Justiça Ambiental como um exercício da cidadania, sendo, assim, um princípio decorrente do respeito "à diversidade cultural, à democratização do acesso aos recursos naturais e à distribuição dos riscos da produção industrial". Nesse sentido, a autora elucida que a continuidade da injustiça ambiental fomenta uma "crise da democracia" (ZHOURI 2008).

Como contraponto ao movimento pela Justiça Ambiental, Giddens (1996) afirma que os impactos negativos estão distribuídos e atingem a todos, sendo, com isso, um movimento global: "a ecotoxicidade afeta a todos, produzindo uma contaminação genérica, por substâncias químicas que atingem indiretamente o meio ambiente por meio de áreas de despejo de detritos, esgotos e por outros canais" (GIDDENS, 1996, p. 256).

Tendo como base de análise a interrelação do acesso ao saneamento básico e a promoção da justiça ambiental, Ataíde e Borja (2017) verificaram a capacidade de um PMSB, principal instrumento da política de saneamento, em promover justiça. Para esse exercício, as autoras usam o conceito de justiça distributiva territorial, proposto por Harvey (1980), baseado em três categorias: necessidade, contribuição do bem comum e mérito. Assim, a distribuição dos serviços públicos de saneamento básico deve considerar: a identificação e a satisfação das necessidades da população urbana e rural em cada território e as tecnologias empregadas em cada meio, respeitando as condições culturais, sociais e ambientais das populações residentes. Recursos extras devem ser alocados para resolução de dificuldades peculiares, de cunho social, natural e físico, e a alocação de recursos deve visar os efeitos multiplicadores interterritoriais. Igualmente, os territórios menos favorecidos devem ser priorizados por meio de mecanismos institucionais, organizacionais, políticos e econômicos. Somados a isso, a participação social nas decisões e o empoderamento das comunidades são essenciais para a aplicação da justiça ambiental e social nos PMSBs (ATAÍDE e BORJA, 2017).

Sendo assim, ao avaliar em específico a abordagem do rural nos PMSBs, o presente artigo busca ser instrumento de sensibilização em relação ao tema da justiça ambiental, contribuindo para que as políticas de saneamento básico possam ser interpretadas à luz de um arcabouço teórico mais amplo e inclusivo, fomentando o avanço efetivo de suas proposições.

\subsection{Políticas Públicas}

Após 100 anos da formação da Liga Pró-saneamento no Brasil, criada em 1918, movimento que visava a encampação pelo Estado das políticas de saneamento e sua ampliação para as áreas rurais (HOCHMAN, 1998; REZENDE e HELLER, 2008), foi publicado, em 2019, o Programa Nacional de Saneamento Rural (PNSR), atualmente denominado Programa Saneamento Brasil Rural (PSBR) (BRASIL, 2019). O PSBR apresenta três eixos: tecnologia, gestão e educação, sendo orientado pelos marcos referenciais da promoção da saúde, erradicação da extrema pobreza e desenvolvimento rural solidário sustentável (BRASIL, 2019). 
Segundo o PSBR, o descaso com o meio rural presente no senso comum é promotor de uma visão do rural como algo atrasado e arcaico e decorre do processo de ocupação do Brasil e da prevalência do modelo de concentração de terra. O rural se apresenta, por isso, como entrave ao desenvolvimento urbano e industrial (BRASIL, 2019). Nesse contexto, Abramoway (2000) contesta a forma de definição do rural no Brasil, que contribui para a visão rústica associada a esse espaço. A Lei Federal 5.172 de 1966 corrobora essa análise. Esse marco legal define como zona urbana aquela que acessa "melhoramentos" sanitários (BRASIL, 1966, art. 32), excluindo, com isso, a presença de serviços e infraestrutura no meio rural, conforme exposto no art. 32 , parágrafo 1 , da lei:

$\S 1^{\circ}$ Para os efeitos deste imposto, entende-se como zona urbana a definida em lei municipal; observado o requisito mínimo da existência de melhoramentos indicados em pelo menos 2 (dois) dos incisos seguintes, construídos ou mantidos pelo Poder Público:

I - meio-fio ou calçamento, com canalização de águas pluviais;

II - abastecimento de água;

III - sistema de esgotos sanitários;

IV - rede de iluminação pública, com ou sem posteamento para distribuição domiciliar;

V - escola primária ou posto de saúde a uma distância máxima de 3 (três) quilômetros do imóvel considerado (BRASIL, 1966, art.32)

Ressalta-se que a universalização do acesso aos serviços de saneamento básico é resguardada pela Lei $n^{\circ} 11.445 / 07$ e trata-se de um princípio que promove a justiça ambiental. 0 marco legal indica para a consideração das áreas urbanas e rurais nas políticas de saneamento no Brasil, que devem considerar as populações quilombolas, as áreas dispersas e indígenas do território, por meio de soluções compatíveis com as características econômicas, sociais e peculiares de cada localidade (BRASIL, 2007).

É preciso reforçar que, embora esteja normatizada sua universalização, o acesso ao saneamento tem reforçado desigualdades estruturais existentes na sociedade brasileira. 0 déficit sanitário foi construído, assim, mediante uma distribuição desproporcional da qualidade e do acesso entre as regiões brasileiras e dentro dos limites municipais, entre o meio rural e o urbano, reforçando cenários de injustiça ambiental. Nesse sentido, observa-se que as populações das regiões Sudeste e Sul possuem um melhor padrão de atendimento do que as regiões Norte e Nordeste. São nítidas, também, diferenças no atendimento entre áreas urbanas e áreas rurais, assim como nas periferias (MORAES e BORJA, 2005).

Tendo em vista que o Plano Municipal de Saneamento Básico é o principal instrumento da Política Municipal de Saneamento Básico (BRASIL, 2010), a não abordagem do meio rural em PMSBs, além de violar a lei $n^{\circ} 11.445 / 07$, reforça a exclusão do rural. Vale destacar que o PMSB tem como função organizar a gestão dos serviços, desde o planejamento até a execução, submetida à regulação, fiscalização e controle social. O Decreto Federal $n^{\circ} 7.217 / 2010$ determinou o prazo de apresentação dos planos para 31 de dezembro de 2013, sendo esse prazo prorrogado pela quarta vez consecutiva para 31 de dezembro de 2022 (BRASIL, 2020, 2017, 2015; 2014; 2010).

A abordagem de todo o território municipal no PMSB tem fundamental papel na luta pela redução das desigualdades sociais e injustiças ambientais, proporcionando a criação de uma agenda pública nesse sentido. 


\section{METODOLOGIA}

O presente estudo tem como objetivo a análise da abordagem do meio rural em Planos Municipais de Saneamento Básico do Brasil como uma forma de promoção da justiça ambiental. Sua construção baseou-se em uma série de etapas.

A priori, foi realizada uma amostragem representativa de municípios das cinco regiões brasileiras, de modo a se criar um panorama nacional. Para a definição da amostra, utilizou-se a Eq. 1 de Triola (1999) e Gomes (2012):

\section{(1) Cálculo da amostragem estatística}

$$
\frac{i c^{2} \times p \times q \times N}{n=e^{2}(N-1)+i c^{2} \times p \times q}
$$

Em que: $n$ : Tamanho da amostra; ic: Intervalo de confiança em desvios padrão; $\mathrm{p}$ : Proporção de municípios que pertencem à categoria de interesse ao estudo;

q:Proporção de municípios que não pertencem à categoria de interesse ao estudo;

$\mathrm{N}$ : tamanho da população;

E: erro máximo admitido.

O tamanho da população considerada no cálculo da amostra foi de 2.738, o qual corresponde à totalidade de municípios que haviam concluído seus respectivos planos até outubro de 2016, de acordo com estudo do Ministério das Cidades (BRASIL, 2017). Ademais, foi considerado um intervalo de confiança em desvios padrão (ic) igual a 2, a fim de alcançar um nível de confiança igual a $95 \%$, e foi admitido um erro amostral de $10 \%$. Uma vez que os valores de proporção dos municípios que pertencem à categoria de interesse do estudo $(p)$ e que não pertencem à essa categoria (q) não são conhecidos, não tendo nenhuma informação sobre o valor esperado, foi considerado o pior cenário, no qual a proporção se distribui em partes iguais, sendo $p=0,5$ e $q=0,5$.

A partir disso, obteve-se como resultado uma amostra de 390 municípios, distribuídos aleatoriamente nas cinco regiões brasileiras e, a posteriori, foi realizada uma busca dos PMSBs de todos os municípios selecionados pela amostragem. Essa busca foi realizada por meio de duas fases:

i. verificação da presença do plano no banco de dados já existente e criado pela equipe do projeto intitulado "SanBas: Capacitação e elaboração de planos municipais de saneamento básico (PMSB) em municípios com população de até 50.000 habitantes do estado de Minas Gerais: uma pesquisa-ação no campo tecnológico, do controle social, da comunicação e do empoderamento nas políticas públicas de saneamento básico", do Departamento de Engenharia Sanitária e Ambiental da Universidade Federal de Minas Gerais (UFMG), em parceria com a Fundação Nacional de Saúde (FUNASA). $O$ desenvolvimento desse banco iniciou-se em dezembro de 2016 e envolve a computação e atualização dos dados em uma planilha com planos de todos os municípios do Brasil.

ii. em caso da não presença do plano no banco de dados, a busca foi realizada via internet, em principal no site da Prefeitura Municipal, da Câmara Municipal, do Diário Oficial, dos comitês de bacia hidrográficas e de órgãos financiadores do PMSB.

O número de planos amostrados e localizados por região brasileira estão apresentados na Tabela 1. 
Tabela 1- PMSBs amostrados e localizados.

\begin{tabular}{|c|c|c|}
\hline Macrorregião do Brasil & Amostragem & PMSBs localizados \\
\hline Sul & 90 & 48 \\
\hline Sudeste & 92 & 47 \\
\hline Macrorregião do Brasil & Amostragem & PMSBs localizados \\
\hline Nordeste & 76 & 24 \\
\hline Centro Oeste & 68 & 39 \\
\hline Norte & 64 & 15 \\
\hline
\end{tabular}

Somado a isso, os municípios brasileiros com PMSB já elaborados até outubro de 2016, bem como aqueles amostrados e os com seus respectivos PMSBs localizados, podem ser visualizados na Fig. 1.

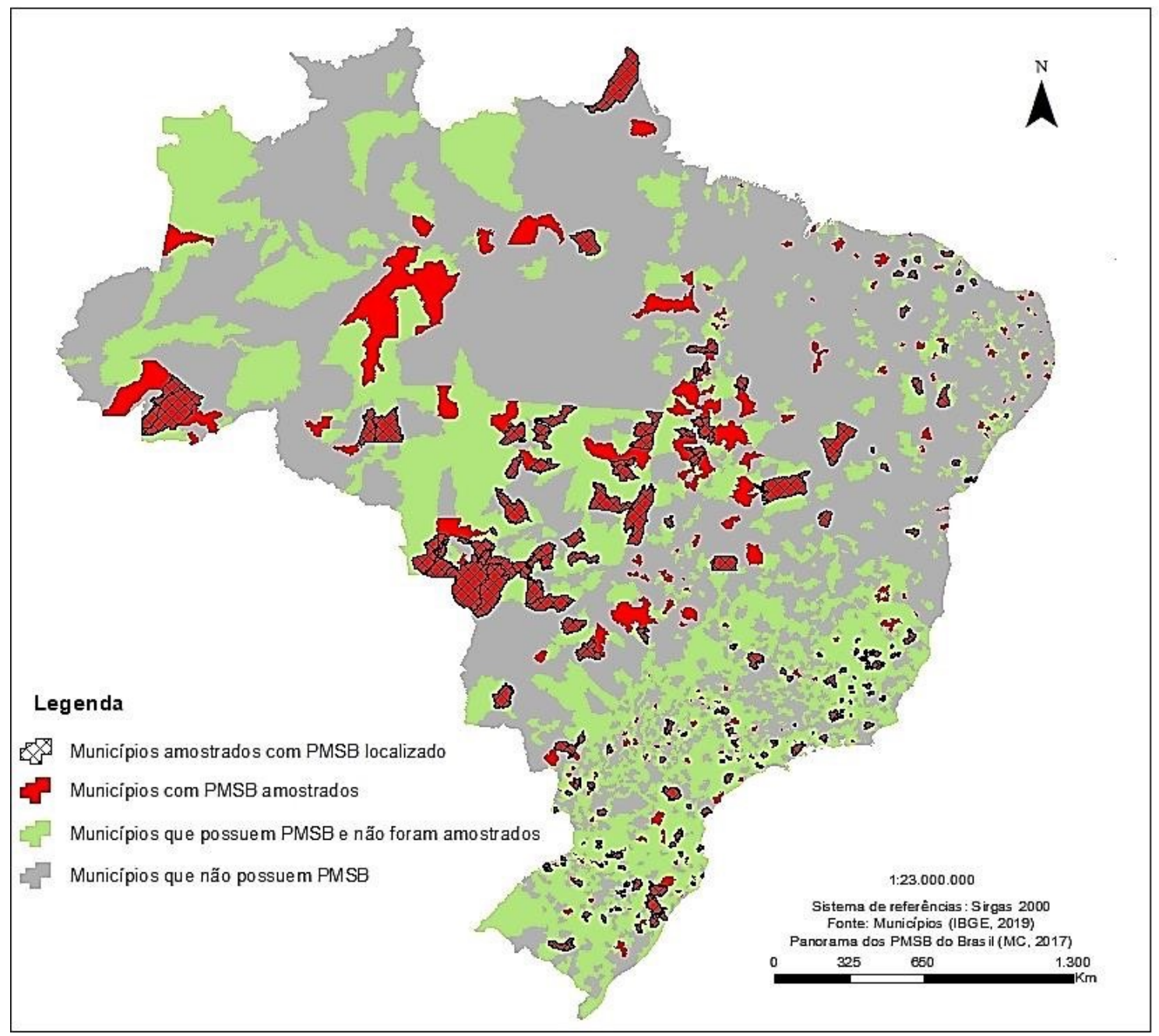

Figura 1 - Panorama de municípios com PMSB amostrados e com PMSB localizado

Para a avaliação da abordagem do meio rural nos planos localizados, foi realizada uma análise de conteúdo do produto referente ao Diagnóstico Técnico-Participativo dos PMSBs. Para isso, foi realizada uma busca da palavra "rural" no produto, verificando-se, com isso, a citação do rural na descrição dos sistemas de todos os eixos do saneamento básico presentes no documento. Por fim, os dados obtidos foram analisados com base na estatística descritiva, via cálculos percentuais e a compilação dos dados em gráficos que permitem a comparação dos resultados obtidos. 


\section{RESULTADOS E DISCUSSÃO}

Além da obrigatoriedade da elaboração dos Planos Municipais de Saneamento Básico, a Lei ${ }^{\circ}$ 11.445/07 impõe a "transparência das ações, baseada em sistemas de informações e processos decisórios institucionalizados" (BRASIL, 2007, p.1). Ademais, essa lei assegura, em seu art. 29, no $5^{\circ}$ inciso, a "ampla divulgação das propostas dos planos de saneamento básico e dos estudos que as fundamentem, inclusive com a realização de audiências ou consultas públicas" (BRASIL, 2007, p. 8) e, em seu art. 26, explana:

[...] a publicidade aos relatórios, estudos, decisões e instrumentos equivalentes que se refiram à regulação ou à fiscalização dos serviços, bem como aos direitos e deveres dos usuários e prestadores, a eles podendo ter acesso qualquer do povo, independentemente da existência de interesse direto (BRASIL, 2007, p. 10).

Tendo em vista a transparência e a divulgação dos PMSBs como princípios da Lei Nacional do Saneamento Básico, as cinco regiões brasileiras encontram-se, portanto, em desconformidade com a lei em questão. Isso é verificado, uma vez que em todas as regiões a porcentagem de planos municipais de saneamento básico não localizada por meio digital foi elevada, como exposto na Fig. 2.

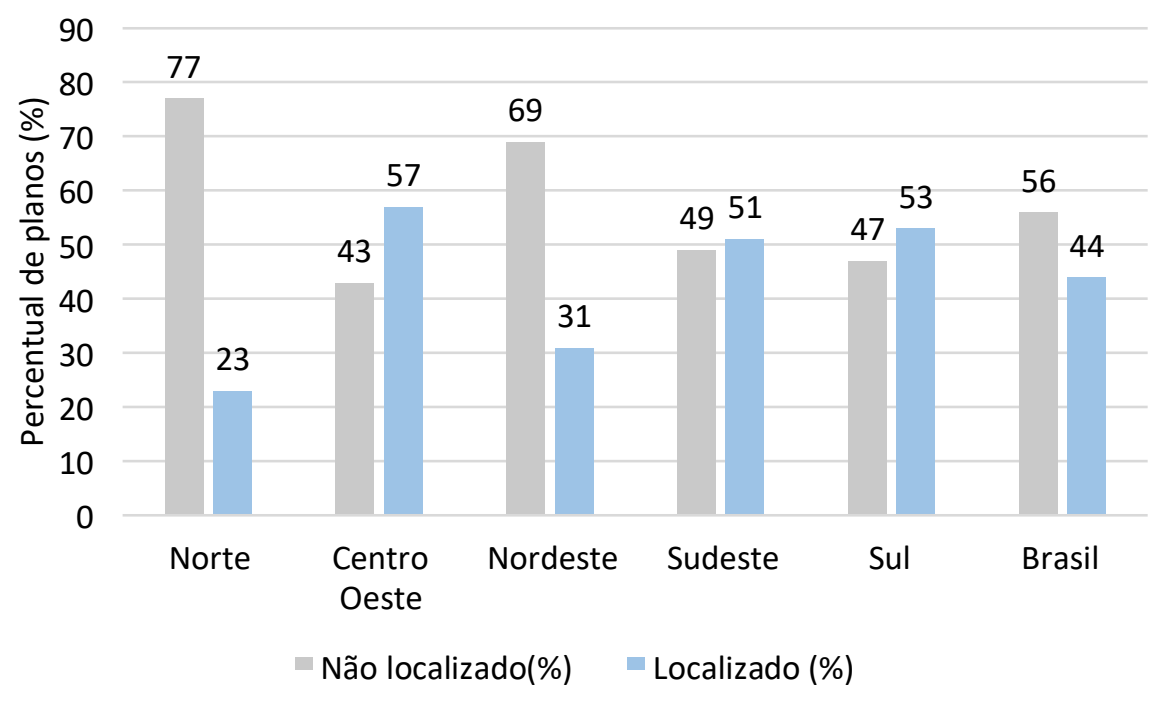

Figura 2 - Percentual de PMSBs localizados por macrorregião do Brasil

Esse desacordo com a norma, contudo, foi maior para as regiões Norte (77\%) e Nordeste (69\%) e em menor grau para o Centro Oeste (43\%), como apresentado na Fig. 2. No âmbito nacional, 56\% dos PMSBs não foram localizados, ou seja, mais da metade dos documentos não estão disponíveis para consulta pública de forma imediata. Em pesquisa realizada por Ferreira et al. (2019), os autores também apontam dificuldades de acesso a PMSBs de municípios das bacias dos rios Paraíba do Sul, Piracicaba, Capivari e Jundiaí em sua porção paulista, além da desinformação identificada dentro do órgão público em relação à existência do PMSB. Ferreira et al. (2019, p. 46) reforçam a importância da disponibilização dos planos municipais de saneamento básico como forma de controle social ao reconhecer a necessidade de os atores sociais se fundamentarem 
"por meio de informação, abertura à consulta, engajamento nas representações, responsabilidade compartilhada, poder e controle dos cidadãos nos processos decisórios".

Importante reafirmar a importância do controle social, um dos princípios da Lei Nacional do Saneamento, para a promoção da justiça ambiental. Piterman (2008) aponta o controle social como elemento fundamental para o gerenciamento e o monitoramento das políticas públicas, a fim de que essas políticas assistam às demandas e carências da sociedade como um todo. Essa autora ainda afirma a necessidade do controle social para a plena eficiência do arcabouço legal associado ao saneamento básico e explana que a inexistência do controle social gera consequências alarmantes por corroborar a inibição de diagnósticos eficientes da realidade de cada localidade e o protagonismo da sociedade como "coagente de mudanças que contemplem de fato suas demandas básicas para uma melhor qualidade de vida" (PITERMAN, 2008, p. 26). Na ausência de controle social, a busca por redução das desigualdades regionais e municipais, com a universalização dos serviços e justiça ambiental, torna-se um desafio ainda maior.

Já em relação à abrangência territorial, entre os planos localizados, como pode ser observado na Fig. 3, o Nordeste apresentou o melhor cenário, com $95,83 \%$ dos planos abordando as áreas rurais e urbanas, seguido do Centro-Oeste, com $94,59 \%$. Outrossim, a região de maior desconformidade é o Sudeste, com $40,43 \%$ dos planos abrangendo apenas o meio urbano. Algumas hipóteses podem ser mobilizadas para explicar - panorama observado, com destaque para a macrorregião Nordeste. Nesse sentido, ressaltase a importância do rural para a região Nordeste, onde estão localizados $46,0 \%$ dos domicílios rurais brasileiros (IBGE, 2010), e seu histórico de associativismo rural (FURTADO, 1989; 1998). No entanto, são necessários estudos mais aprofundados no sentido de revelar as razões das diferenças macrorregionais observadas.

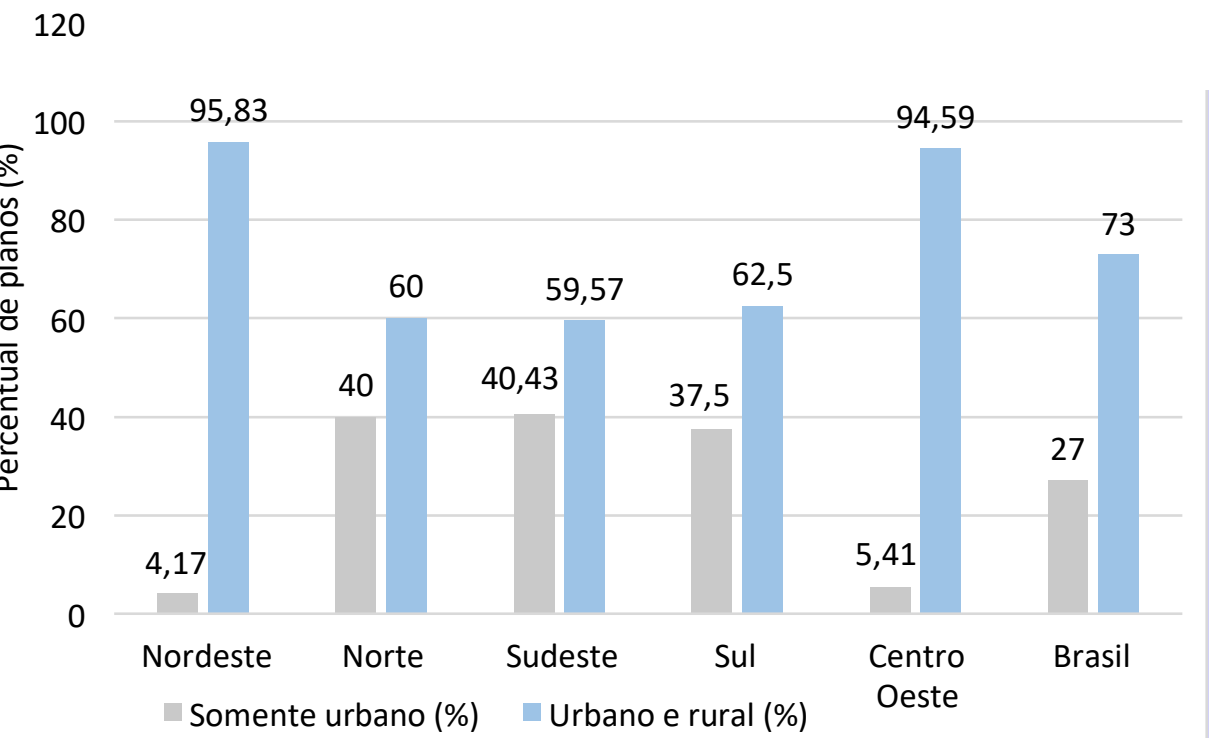

Figura 3 - Abrangência territorial dos PMSBs analisados por macrorregião do Brasil 
Somado a isso, na Fig. 4 pode ser visualizado o panorama dos municípios cujos planos abor- daram somente o meio urbano e aqueles que abrangeram ambos os meios, rural e urbano.

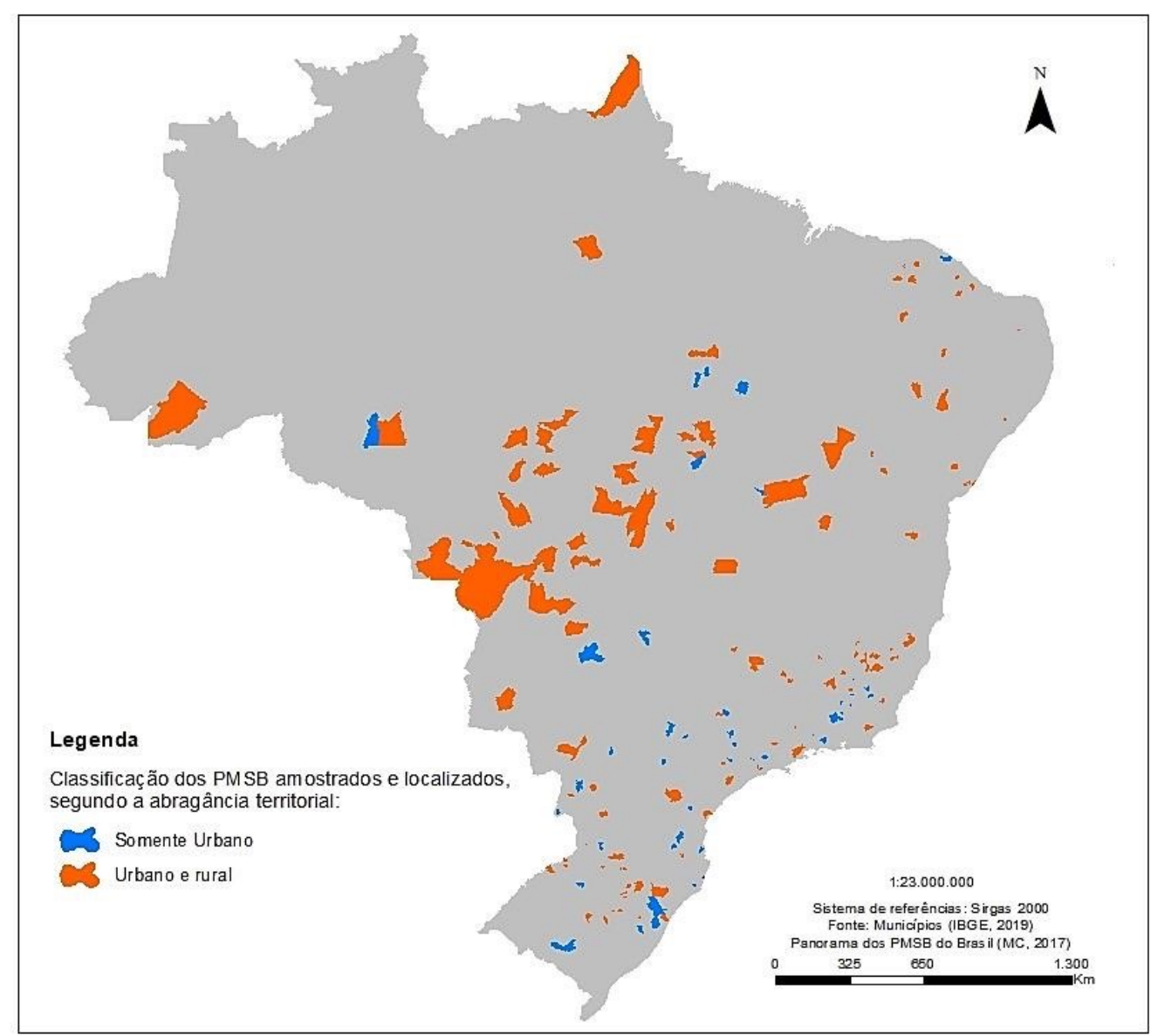

Figura 4 - Panorama da abordagem territorial dos planos localizados

Ao analisar a situação nacional, observa-se que há um total de 127 (73\%) planos municipais encontrados em conformidade com a Lei 11.445/07, no que tange à presença do diagnóstico ambiental das áreas rurais e urbanas do município. Por outro lado, há 46 planos com incoerência (27\%). Nota-se, com esse resultado, uma predominância do nível de importância dada a algumas áreas do território de um município, em detrimento das demais, já que a zona urbana se torna algo inerente ao plano, isto é, já é pressuposta a presença do diagnóstico dos serviços de saneamento básico desse território nos planos, enquanto as áreas rurais não são enquadradas no mesmo patamar. Isso ocorre ao se verificar que em $0 \%$ dos planos foram abordadas apenas as zonas rurais. Ferreira et al. (2019) também identificaram o planejamento municipal em saneamento como uma construção de enfoque majoritário urbanístico, não incluindo as áreas rurais nas políticas ambientais na mesma proporção que as urbanas.

Ressalta-se que essa disparidade de relevância e abordagem desrespeita os princípios da universalização do acesso aos serviços de saneamento básico, da equidade e do atendimento às demandas e condições específicas de cada localidade, os quais são normatizados pela Lei Nacional do 
Saneamento Básico (BRASIL, 2007). Tendo em vista que "abordagens multidisciplinares, intersetoriais, multiculturais e participativas" devem pleitear o planejamento de soluções a fim de obter a universalização do saneamento rural (Silva et al., 2019, p. 73), a abordagem do rural no plano constitui-se como etapa primária para a universalização do saneamento, de forma integrada e equitativa. A negligência dada ao meio rural, em $27 \%$ dos municípios brasileiros, reforça, assim, a exclusão dessa parcela da população frente às políticas públicas, a qual é evidenciada e reafirmada durante o período de vigência de 20 anos no qual o PMSB está inserido.

Sob a perspectiva da participação social, também instituída pela Lei $n^{\circ} 11.445 / 07$, observa-se que a não abordagem do rural nos PMSBs indica o não envolvimento das comunidades rurais em sua elaboração. Com isso, a não contemplação das áreas rurais transforma a construção do PMSB em um processo não democrático e centralizado, isentando o rural das políticas públicas e das tomadas de decisão, o que salienta uma conjuntura pautada na injustiça ambiental, como demonstrado por Socott (2014) e por Acserald et al. (2009).

Silva et al. (2019, p.70) indicam que, no Brasil, não existe uma confrontação enfática às desigualdades, de modo que "um panorama de exclusão sanitária generalizado impõe às populações rurais piores condições de saúde e qualidade de vida", evidenciando a precária situação do setor de saneamento básico na qual o meio rural se insere. Constata-se, portanto, um elevado nível de demandas necessárias para que o cenário do saneamento rural no Brasil evolua e alcance sua universalização, de modo a garantir justiça ambiental aos moradores da zona rural, promovendo acesso aos recursos e serviços, bem como reduzindo sua exposição ao custo ambiental, o qual se refere às consequências da ausência de saneamento básico, que restringem a salubridade ambiental e o bem-estar social.

No aspecto da qualidade da saúde da população, tem-se como exemplo de insalubridade a disseminação de enfermidades associadas à ausência ou à ineficiência de serviços de saneamento básico, como diarreias e doenças parasitárias, dentre elas: as hepatites infecciosas, as gastroenterites, a esquistossomose, a poliomielite, a amebíase, a giardíase, a cólera, a febre tifoide, entre outras (MORAES e BORJA, 2005). Já a respeito do meio físico, tem-se os impactos negativos decorrentes da pressão antrópica sobre o meio ambiente, como a degradação e o uso irracional dos recursos naturais, a contaminação do solo e as alterações do uso e ocupação do solo, fatores que modificam a dinâmica do meio e devem ser devidamente regularizados e monitorados.

Nesse âmbito, atesta-se que o meio rural necessita de maior enfoque para garantir saúde aos residentes e o atendimento aos seus direitos básicos como cidadãos. Para isso, requer-se a compreensão do meio rural como uma realidade diferente do urbano, assim como as divergências entre a dinâmica das próprias comunidades rurais, de modo a formular propostas singulares para cada uma, levando em consideração suas limitações, mas sem a redução da qualidade e da eficiência dos serviços de saneamento básico. Nesse sentido, os PMSBs têm relevância indubitável como instrumento de gestão, diagnóstico, promoção de metas, projetos e programas para os serviços de saneamento básico, tendo como base de elaboração a participação social. O PSBR se enquadra como uma importante referência para o exercício de compreensão do rural para elaboração de PMSBs integrados e equânimes, visando, assim, à inserção dessa parcela do território municipal nos documentos (BRASIL, 2019). 


\section{CONSIDERAÇÕES FINAIS}

No Brasil, o atendimento universal da população e a qualidade dos serviços de saneamento básico permanecem como um desafio. Os dados apresentados nesse estudo indicam que $56 \%$ dos municípios que declaram ter PMSB não disponibilizam os mesmos por meio digital, de modo que os PMSBs não estão prontamente disponíveis para consulta pública. Isso constitui-se como indicativo da ausência de transparência e, consequentemente, do controle social.

A respeito da abrangência territorial, em $27 \%$ dos PMSBs localizados as áreas rurais não foram compreendidas, contribuindo para a geração de injustiça ambiental, tendo em vista que a abordagem total do território municipal no PMSB é fundamental para que toda a sociedade seja assistida pelas políticas públicas. Com isso, o país não garante direitos básicos dos cidadãos, o que corrobora a exclusão social de parcelas da sociedade, as quais são privadas das mesmas oportunidades de qualidade de vida daqueles com acesso aos serviços de saneamento básico. Somado a isso, ao não incluir as áreas rurais no PMSB, cria-se um cenário de vazio de políticas públicas para o saneamento rural. Assim, o Estado, historicamente, atua de forma desarticulada, fragmentada, pontual e desordenada, fazendo-se necessária a abordagem das áreas rurais no PMSB.

A inserção do rural e suas particularidades são essenciais para modificar o quadro atual de injustiça ambiental para as populações que ali residem. Reforça-se, nesse sentido, o papel do PSBR como norteador da elaboração dos PMSBs e da incorporação do rural nos documentos. Destaca-se, também, a essencialidade da participação popular e do controle social na construção da universalização do acesso ao saneamento com equidade e integralidade. Por fim, salienta-se que o titular dos serviços de saneamento básico, responsável pela elaboração dos PMSBs sob os princípios da lei 11.445/2007 (BRASIL, 2007, art.9) e de seu Decreto Regulamentador 7.217/2010 (BRASIL, 2010), deve, portanto, ter maior atuação e acompanhamento do seu processo de construção, a fim de assegurar a abordagem do rural, cumprindo com o estabelecido no marco legal supracitado.

\section{AGRADECIMENTOS}

Os autores agradecem ao Departamento de Engenharia Sanitária e Ambiental da UFMG e aos membros do Grupo de Pesquisa em Políticas Públicas e Gestão em Saneamento da UFMG, à Equipe UFMG Projeto SanBas e à Fundação Nacional de Saúde Funasa pelo financiamento da pesquisa.

\section{CONTRIBUIÇÃO DOS AUTORES}

Conceitualização: Barra BF, Franco R, Gomes UAF; Metodologia: Franco R, Gomes UAF; Investigação: Franco, R, Barra BF, Gomes UAF; Redação - Primeira versão: Franco R e Barra BF; Redação - Revisão \& Edição: Franco, R, Barra BF, Gomes UAF; Aquisição de Financiamento: Gomes UAF; Recursos: Gomes UAF; Supervisão: Gomes UAF

\section{REFERÊNCIAS}

ABRAMOVAY, R. Funções e medidas da ruralidade no desenvolvimento contemporâneo. Texto para discussão nº 702. Brasília: IPEA, 2000.

ACSELRAD, H. Justiça ambiental e Construção Social do risco. Abep - Associação brasileira de estudos populacionais. 2002. Disponível em: <http://www.abep.org.br/ abeporgb/publicacoes/ index.php/anais/article/view/1159>. Acesso em: 27 ago. 2019.

ACSELRAD, H.; HERCULANO, S.; PÁDUA, J. A. A justiça ambiental e a dinâmica das lutas socioambientais no Brasil - uma introdução. In: ______. (Org.). Justiça Ambiental e Cidadania. 2. ed. Rio de Janeiro: Relume Dumará; Fundação Ford, 2004. p. 9-20.

ACSELRAD, H.; MELLO, C. C. A.; BEZERRA, G. N. O que é Justiça ambiental. Rio de Janeiro: Garamond, 2009. 160p. 
ATAÍDE, G. V. T. L.; BORJA, P. C. Social and environmental justice in basic sanitation: a view on municipal planning experiences. Revista Ambiente e Sociedade. São Paulo, vol. XX, n² 2, p. 61-78, jul.-set. 2017. https://doi.org/10.1590/1809-4422ASOC74R1V2032017

BRASIL. Lei $n^{\circ} 11.445$, de 5 de janeiro de 2007. Estabelece diretrizes nacionais para o básico; altera as Leis nos 6.766, de 19 de dezembro de 1979, 8.036, de 11 de maio de 1990, 8.666, de 21 de junho de 1993, 8.987, de 13 de fevereiro de 1995; revoga a Lei no 6.528, de 11 de maio de 1978; e dá outras providências. Disponível em: \&lt;http://www.planalto.gov.br/ccivil_03/_ ato2007-2010/2007/lei//11445.htm\&gt;. Acesso em: 17 fev. 2019.

BRASIL. Lei $n^{\circ} 5.172$, de 25 de outubro de 1966. Dispõe sobre o Sistema Tributário Nacional e institui normas gerais de direito tributário aplicáveis à União, Estados e Municípios. Diário Oficial da União, Brasília, DF, 25 de outubro de 1966.

BRASIL. Decreto $n^{\circ} 7217$, de 21 de junho de 2010. Regulamenta a lei $n^{\circ} 11.445$, de 5 de janeiro de 2007, que estabelece diretrizes nacionais para o saneamento básico, e dá outras providências. Brasília, 2010.

BRASIL. Decreto $n^{\circ} 8.211$, de 21 de março 2014. Altera o Decreto $n^{\circ} 7.217$, de 21 de junho de 2010, que regulamenta a Lei $n^{\circ} 11.445$, de 5 de janeiro de 2007, que estabelece diretrizes nacionais para o saneamento básico. Brasília, 2014.

BRASIL. Decreto $n^{\circ} 8.629$, de 30 de dezembro de 2015. Altera o Decreto $\mathrm{n}^{\circ} 7.217$, de 21 de junho de 2010, que regulamenta a Lei $n^{\circ} 11.445$, de 5 de janeiro de 2007, que estabelece diretrizes nacionais para o saneamento básico. Brasília, 2015.

BRASIL. Decreto No 10.203, de 22 de janeiro de 2020. Altera o Decreto $\mathrm{n}^{\circ} 7.217$, de 21 de junho de 2010, que regulamenta a Lei $n^{\circ} 11.445$, de 5 de janeiro de 2007, que estabelece diretrizes nacionais para o saneamento básico. Brasília, 2017.

BRASIL. Ministério da Saúde. Fundação Nacional da Saúde. Programa Nacional de Saneamento Rural: PNSR. Fundação Nacional de Saúde. Edição Interna. Novembro de 2019. 264 p.

BRASIL. Ministério das Cidades. Panorama dos planos municipais de Saneamento básico no Brasil. Edição: Janeiro de 2017. 40p.

BRASIL. Plano Nacional de Saneamento Básico. Brasília: Ministério do Desenvolvimento Regional. Secretária de Saneamento. 2019a.

BRASIL. Plano Nacional de Saneamento Básico. Brasília: Ministério das Cidades. Secretaria Nacional de Saneamento. 2013.

BULLARD, R. Enfrentando o racismo ambiental no século XXI. Tradução de C. M. de Freitas. In: ACSELRAD, H.; HERCULANO, S.; PÁDUA, J. A. (Org.). Justiça Ambiental e Cidadania. 2. ed. Rio de Janeiro: Relume Dumará; Fundação Ford, 2004. p. 41-68.
FARIA, M. T. S. Determinantes da presença de soluções sanitárias: um estudo sobre a população de baixa renda no Brasil. Dissertação (Mestrado em Saneamento, Meio Ambiente e Recursos Hídricos). Escola de Engenharia. Universidade Federal de Minas Gerais. Belo Horizonte. 2018. 178p.

FERREIRA, L. A. F.; RIBEIRO, P. S. C.; ANDRADE, I. C. M.; GUIDES, R. M.; SANTOS, L. O. L.; CRUZ, L. M. O.; SANTOS, M. R. R.; REZENDE, S. Saneamento rural no planejamento municipal: lições a partir do Programa Nacional de Saneamento Rural (PNSR). Revista DAE. São Paulo, v. 67, n. 220, p. 36-51, 2019. https://doi.org/10.4322/ dae.2019.054

FURTADO, C. A fantasia desfeita. São Paulo: Paz e Terra, 1989.

FURTADO, C. Seca e poder: entrevista com Celso Furtado. São Paulo: Fundação Perseu Abramo, 1998.

GIDDENS, A. Para além da esquerda e da direita. São Paulo: Unesp, 1996. 256 p.

GOMES, U. A. F. Água em situação de escassez: Água de chuva para quem?. 369f. Tese (Doutorado em Saneamento, Meio Ambiente e Recursos Hídricos). Escola de Engenharia, Universidade Federal de Minas Gerais, Belo Horizonte, 2012.

HARVEY, D. A Justiça Social e a Cidade. São Paulo: Hucitec, 1980.

HERCULANO, S. Riscos e desigualdade social: a temática da Justiça Ambiental e sua construção no Brasil. 2002. Disponível em: <http://www.anppas.org.br/>. Acesso em: 16 de novembro de 2019.

HOCHMAN, Gilberto. A era do saneamento: as bases da política de saúde pública no Brasil. São Paulo: Editora Hucitec Anpocs, 1998.

IBGE - INSTITUTO BRASILEIRO DE GEOGRAFIA E ESTATÍSTICA. Sistema IBGE de Recuperação Automática - SIDRA. Censo Demográfico: 2010. Disponível em: <https://sidra.ibge.gov.br/ pesquisa/censo-demografico/demografico-2010/amostrafamilias-e-domicilios>. Acesso em: 28 out. 2020.

LUZZA, M. O pobre saneamento ou o saneamento pobre? Uma análise da ausência de soluções sanitárias da população brasileira de baixa renda cadastrada no cadúnico. Dissertação (Mestrado em Saneamento, Meio Ambiente e Recursos Hídricos). Escola de Engenharia. Universidade Federal de Minas Gerais. Belo Horizonte. 2019.139p.

MORAES, L. R. S.; BORJA, P. C. Política e plano municipal de saneamento ambiental: experiências e recomendações. 2005. Disponível em: <http://bvsms.saude.gov.br/bvs/publicacoes/ politica_plano_municipal_saneamento.pdf>. Acesso em: 10 out. 2019.

PITERMAN, A. O controle social e as políticas públicas de saneamento: uma avaliação em municípios pertencentes à Bacia do Rio das Velhas. 2008. 237 f. Dissertação (mestrado) - Universidade Federal de Minas Gerais, Departamento de 
Engenharia Sanitária e Ambiental, 2008. Disponível em: <https://repositorio.ufmg.br/bitstream/1843/ENGD7LTPBX/1/ anapiterman357.pdf>. Acesso em: 23 out. 2019.

RAMMÊ, R. S. Da justiça ambiental aos direitos e deveres ecológicos: conjecturas políticos-filosóficas para uma nova ordem jurídico-ecológica. 2. ed. Caxias do Sul: Educs, 2012. 203 p. Disponível em: <https://www.ucs.br/site/midia/arquivos/ JUSTICA_AMBIENTAL_EDUCS_EBOOK.pdf >. Acesso em: 23 out. 2019.

REZENDE, S. C.; HELLER, L. 0 saneamento no Brasil: Políticas e Interfaces. Belo Horizonte: Editora UFMG, 2008. 387 p.

SALES, B. M. Caracterização dos Determinantes da Exclusão Sanitária nos Domicílios Rurais Brasileiros. Dissertação (Mestrado em Saneamento, Meio Ambiente e Recursos Hídricos). Escola de Engenharia. Universidade Federal de Minas Gerais. Belo Horizonte. 2018. 170p.

SCOTT, D. N. What is Environmental Justice? Osgoode Legal Studies Research Paper. Toronto, v.10, n.72, 2014. Disponível em: <https://digitalcommons.osgoode.yorku. ca/cgi/viewcontent.cgi?referer=https://www.google.c om/\&httpsredir=1\&article=1003\&context=olsrps >. Acesso em: 07 out. 2019. https://dx.doi.org/10.2139/ssrn.2513834

SILVA, B. B.; NOGUEIRA, C. D.; ANDRADE, M.; SILVEIRA, R. B. S.; REZENDE, S. Evidenciando experiências positivas em saneamento básico: visões do Programa Nacional de Saneamento Rural (PNSR). Revista DAE. São Paulo, v. 67, n. 220, p. 69-86, 2019. https://doi. org/10.4322/dae.2019.056

TRIOLA, M. F. Introdução à estatística. 7 ed. Rio de Janeiro: LTC S.A., 1999. 412 p.

ZHOURI, A. Justiça ambiental, diversidade cultural e accountability: Desafios para a governança ambiental. Revista Brasileira de Ciências Sociais. São Paulo, v. 23, n. 68, p. 97107, 2008. Disponível em: <https://www.redalyc.org/pdf/107/10713666011.pdf> Acesso em: 07 out. 2019. https://doi.org/10.1590/S010269092008000300007

[WHO] WORLD HEALTH ORGANIZATION; [UNICEF] UNITED NATIONS CHILDREN'S FUND. Joint Monitoring Programme. For Water Supply and Sanitation. Data and estimates: tables. Disponível em: < https://washdata.org/data/>. Acesso em: 23 de novembro de 2019. 